\title{
Piperine effectively protects primary cultured atrial myocytes from oxidative damage in the infant rabbit model
}

\author{
YONGJIANG MA ${ }^{1}$, MIAO TIAN ${ }^{1}$, PIN LIU ${ }^{2}$, ZILING WANG $^{3}$, YUAN GUAN ${ }^{1}$, \\ YAN LIU $^{1}$, YUTANG WANG ${ }^{1}$ and ZHAOLIANG SHAN ${ }^{1}$ \\ Departments of ${ }^{1}$ Cardiology and ${ }^{2}$ Clinical Pharmacology and Pharmacy, Chinese PLA General Hospital, Beijing 100853; \\ ${ }^{3}$ Institute of Blood Transfusion Medicine, Academy of Military Medical Sciences, Beijing 100850, P.R. China
}

Received October 10, 2013; Accepted May 21, 2014

DOI: $10.3892 / \mathrm{mmr} .2014 .2554$

\begin{abstract}
Piperine is an important active component of the Chinese herb Large leaf moss. The aim of this study was to investigate the effects of piperine on oxidative stress. An oxidative stress model was developed in rabbit atrial cells treated with low concentrations of hydrogen peroxide $\left(\mathrm{H}_{2} \mathrm{O}_{2}\right)$. A primary cell culture of the atrial cells was established and the cells were randomly divided into three groups: A piperine group, an $\mathrm{H}_{2} \mathrm{O}_{2}$ group and a control group. The results demonstrated that the cell viability and superoxide dismutase activity in the piperine group were significantly higher than in the $\mathrm{H}_{2} \mathrm{O}_{2}$ group $(\mathrm{P}<0.05)$, and the expression levels of malondialdehyde and glutathione were significantly reduced in the piperine group compared with the $\mathrm{H}_{2} \mathrm{O}_{2}$ group $(\mathrm{P}<0.05)$. The intracellular free calcium concentration and the expression level of mitochondrial mRNA in the piperine group were also significantly lower than in the $\mathrm{H}_{2} \mathrm{O}_{2}$ group $(\mathrm{P}<0.05)$. In conclusion, piperine was important in protecting the primary rabbit atrial cells from oxidative stress.
\end{abstract}

\section{Introduction}

Large leaf moss, the dried or fresh grass of bryaceae, such as Rhodobryum roseum (Hedw.) Limpr. [Mnium roseum Hedw.], $R$. giganteum (Schwaegr) par. and $R$. giganteum par. (1-3), is a traditional herbal remedy widely used in the Yunnan province of China. Large leaf moss is commonly used to treat diseases, including heart palpitations, chest tightness and neurasthenia.

Myocardial ischemic injury is associated with the generation of reactive oxygen species (ROS); it has been demonstrated that the production of ROS increased and antioxidant enzyme activity decreased during myocardial ischemia (4). Oxidative stress resulting from oxygen free radical production may

Correspondence to: Mr. Zhaoliang Shan, Department of Cardiology, Chinese PLA General Hospital, 28 Fuxing Road, Haidian, Beijing 100853, P.R. China

E-mail: shanzhaoliang1960@163.com

Key words: piperine, atrium, primary cell, oxidative stress, protective effect exceed the capacity of endogenous free radical scavenging mechanisms, resulting in lipid peroxidation and DNA damage in mitochondria $(5,6)$. Data have indicated that cellular oxidative stress is important in the pathogenesis of atrial fibrillation (7). Results from another study have indicated that trying to prevent and avoid oxidative damage to atrial cells may prevent and relieve the development of atrial fibrillation to a certain extent (8).

In a study of monomeric compounds in Large leaf moss, piperine and pepper acid methyl ester protected cardiomyocytes from the injury induced by hydrogen peroxide $\left(\mathrm{H}_{2} \mathrm{O}_{2}\right)$, and piperine effectively protected ventricular myocytes from the injury induced by oxygen radicals (1). In the present study, an oxidative injury model with low concentrations of $\mathrm{H}_{2} \mathrm{O}_{2}$ was used to analyze the key steps in the oxidative stress response and further investigate the protective effect of piperine on primary atrial cells in the oxidative injury model.

\section{Materials and methods}

Reagents. The superoxide dismutase (SOD), malondialdehyde (MDA) and glutathione (GSH) kits were from Jiancheng Bioengineering Corporation (Nanjing, China), and piperine and MTT were obtained from Sigma-Aldrich (St. Louis, MO, USA). Dulbecco's modified Eagle's medium (DMEM), 3\% $\mathrm{H}_{2} \mathrm{O}_{2}$ and fetal bovine serum were purchased from Gibco-BRL (Carlsbad, CA, USA). The penicillin-streptomycin mixture and $0.25 \%$ trypsin-EDTA were supplied by Beijing Solarbio Science \& Technology Co., Ltd. (Beijing, China). The primer probes and SYBR Green were purchased from Shanghai ShineGene Molecular Biotech, Inc. (Shanghai, China). Fluorochrome Fluo-2/acetoxymethyl ester (Fura-2 AM) was obtained from Anaspec (Fremont, CA, USA).

Animals. Neonatal New Zealand rabbits (age, 3-5 days; weight, 150-200 g) were obtained from the Experimental Animal Center of Military Medical Sciences (Beijing, China) and housed in specific pathogen-free conditions. The protocols were approved by the Institutional Animal Care and Use Committee of General Hospital of People's Liberation Army. All procedures were in accordance with the Declaration of Helsinki of the World Medical Association. 
Animal grouping and primary culture of atrial muscle cells. A total of 18 animals were randomly divided into three groups: Piperine, $\mathrm{H}_{2} \mathrm{O}_{2}$ and control groups. Briefly, following sacrifice by injection of $\sim 10 \mathrm{ml}$ air into the ear vein, the neonatal rabbit was fixed in a supine position and the chest skin was disinfected. The chest wall was cut and removed along the right edge of the sternum. The heart was rapidly removed and washed in D-Hanks fluid (Baihao, Tianjin, China) and the blood was removed. The left and right atria were washed with serum-free medium under sterile conditions and cut into small $\sim 1$-mm diameter sections with ophthalmic scissors. A volume of $5 \mathrm{ml} 0.08 \%$ trypsin was added to the tissue sections, which were incubated in a $37^{\circ} \mathrm{C}$ water bath for $5 \mathrm{~min}$. Digestion was then terminated by adding serum to the medium. A single cell suspension culture was prepared and the concentration of cells was adjusted to $1 \times 10^{5} / \mathrm{ml}$. To inhibit the growth of fibroblast cells, $1 \mathrm{ml}$ of $0.1 \mathrm{mmol} / 1$ bromodeoxyuridine (Sigma-Aldrich) was added. The cultures were incubated at $37^{\circ} \mathrm{C}$ in a humidified incubator with $5 \% \mathrm{CO}_{2}$.

The primary atrial myocytes in the piperine group were pretreated with $7 \times 10^{-6} \mathrm{~mol} / 1$ piperine for $1 \mathrm{~h}$, then $100 \mu \mathrm{mol} / 1$ $\mathrm{H}_{2} \mathrm{O}_{2}$ was added and the cells were incubated for $2 \mathrm{~h}$. The $\mathrm{H}_{2} \mathrm{O}_{2}$ and control groups were treated with $100 \mu \mathrm{mol} / 1 \mathrm{H}_{2} \mathrm{O}_{2}$ or phosphate-buffered saline (PBS) for $2 \mathrm{~h}$, respectively.

Detection of cell viability. The cell concentrations were adjusted to $1 \times 10^{6}$ cells $/ \mathrm{ml}$ in DMEM supplemented with $10 \%$ fetal calf serum. Samples of the suspensions $(100 \mu \mathrm{m})$ were dispensed into 96-well round-bottom culture plates (Costar, Cambridge, MA, USA) and incubated for $72 \mathrm{~h}$ at $37^{\circ} \mathrm{C}$ in a $5 \%$ $\mathrm{CO}_{2}$ humid incubator. Cell proliferation was then determined with the MTT assay (9).

Detection of oxidative stress markers SOD, MDA and GSH. Supernatant $(50 \mu \mathrm{l})$ was extracted from the myocardial cell cultures. SOD expression levels were determined with the xanthine oxidase method, MDA expression levels were measured by thiobarbituric acid assay and GSH expression levels were determined by a colorimetric method. All assays were performed according to the manufacturer's instructions of the respective kits.

Measurement of intracellular $\mathrm{Ca}^{2+}$. Intracellular $\mathrm{Ca}^{2+}$ levels were determined with $\mathrm{Ca}^{2+}$-sensitive Fluo-2/acetooxymethyl ester by a Becton Dickinson FACS Calibur flow cytometer (Becton-Dickinson, Franklin Lakes, NJ, USA) or a Perkin-Elmer LS 55 fluorescence spectrophotometer (Perkin-Elmer, Waltham, MA, USA) $(10,11)$. The cells were incubated with $3 \mu \mathrm{M}$ Fluo-2/AM at $37^{\circ} \mathrm{C}$ for $30 \mathrm{~min}$ in the dark following treatment with salidroside and $\mathrm{H}_{2} \mathrm{O}_{2}$ as described. The cells were then gently rinsed three times with D-Hanks solution and the fluorescence was analyzed by flow cytometry. Fluo-2/AM bound to cytoplasmic free calcium generates a strong fluorescence at an excitation wavelength of $330-350 \mathrm{~nm}$, which is reduced at the $380 \mathrm{~nm}$ excitation wavelength. Thus, the fluorescence ratio of 340 to $380 \mathrm{~nm}$ was used to detect the intracellular calcium ion concentrations.

Quantitative analysis of mitochondrial mRNA in atrial myocytes. TotalRNA was isolated with an RNApure kit(Bioteke,
Beijing, China) and retrotranscribed with MLV-reverse transcriptase (Invitrogen Life Technologies, Carlsbad, CA, USA) with random primers. Reverse transcription-quantitative polymerase chain reaction (RT-qPCR) was performed by real-time PCR ABI Prism 7500 (Applied Biosystems China, Beijing, China), using 40 cycles of $95^{\circ} \mathrm{C}$ for $12 \mathrm{sec}$ and $60^{\circ} \mathrm{C}$ for $1 \mathrm{~min}$ with SYBR Green. The primers were designed using Primer Premier, version 5 (www.premierbiosoft.com and OLIGO Primer Analysis Software, version 6 (oligo.net). The sequences of the primers were 5'-AGGATGGTAGCAAGGAGGAAG-3' and 5'-ACCCTGGAGCGATGTGGA-3'. The length of p22-phox (Oryctolagus cuniculus) was $137 \mathrm{bp}$.

Statistical analysis. Data were analyzed using SPSS software (SPSS Inc., Chicago, IL, USA). All data are expressed as the mean \pm standard deviation or standard error of the mean. $\mathrm{P}<0.05$ was considered to indicate a statistically significant difference.

\section{Results}

Primary culture of atrial myocytes and morphological observation. After $72 \mathrm{~h}$ culture, cells with a variety of shapes were visible under an inverted microscope, although the cell morphology was dominated by spindle, triangular and irregular shapes (Fig. 1A). Hemotoxylin and eosin staining of the cells is presented in Fig. 1B. Certain adherent cardiomyocytes formed multicellular beating cell clusters within $24 \mathrm{~h}$.

Cell viability of primary atrial myocytes increases following piperine treatment. In order to determine the role of piperine on the cell viability of primary atrial myocytes, an MTT assay was performed. The results demonstrate that the cell viability of the primary atrial myocytes significantly increased following treatment with piperine compared with the cells only treated with $\mathrm{H}_{2} \mathrm{O}_{2}$. Furthermore, the cell viability increased in a time-dependent manner, as analyzed by MTT (Fig. 2A). The results detected by MTT were consistent with those observed with FACS analysis (Fig. 2B).

Detection of oxidative stress markers SOD, MDA and GSH. The levels of oxidative stress markers were detected in different groups. As shown in Fig. 3 and Table I, the mean SOD production in the piperine group was significantly higher than that in the $\mathrm{H}_{2} \mathrm{O}_{2}$ group $(\mathrm{P}<0.05)$ and the expression levels of MDA and GSH in the culture supernatant of primary myocardial cells in the piperine group were significantly lower than those in the $\mathrm{H}_{2} \mathrm{O}_{2}$ group $(\mathrm{P}<0.01)$. Untreated cells served as negative controls.

Detection of the intracellular calcium concentration. Impaired oxidative phosphorylation may result in lowered ATP synthase function and reduce the ability of the mitochondria to synthesize ATP. In addition, oxidative stress may reduce the activity of ATP-dependent ion pumps in the cell membrane and intracellular calcium levels may become elevated. Thus, the intracellular calcium levels in the different groups were examined. As shown in Fig. 4, the intracellular calcium concentration was significantly lower in the group treated with piperine than in those treated with $\mathrm{H}_{2} \mathrm{O}_{2}$ alone $(\mathrm{P}<0.01)$. 
Table I. Effects of piperine on oxidative stress markers SOD, MDA and GSH.

\begin{tabular}{lcrr}
\hline Group & SOD $(\mathrm{U} / \mathrm{l})$ & MDA $(\mathrm{U} / \mathrm{l})$ & $\mathrm{GSH}(\mu \mathrm{M} / \mathrm{ml})$ \\
\hline Control & $1706.666 \pm 13.278$ & $0.333 \pm 0.101$ & $0.189 \pm 0.047$ \\
$\mathrm{H}_{2} \mathrm{O}_{2}$ & $202.423 \pm 65.498$ & $12.593 \pm 0.201$ & $3.869 \pm 0.192$ \\
Piperine & $407.272 \pm 59.598^{\mathrm{a}}$ & $4.965 \pm 0.335^{\mathrm{a}}$ & $2.485 \pm 0.117^{\mathrm{a}}$
\end{tabular}

${ }^{a} \mathrm{P}<0.05$ compared with the $\mathrm{H}_{2} \mathrm{O}_{2}$ group. SOD, superoxide dismutase; MDA, malondialdehyde; GSH, glutathione. $\mathrm{H}_{2} \mathrm{O}_{2}$, hydrogen peroxide.

A

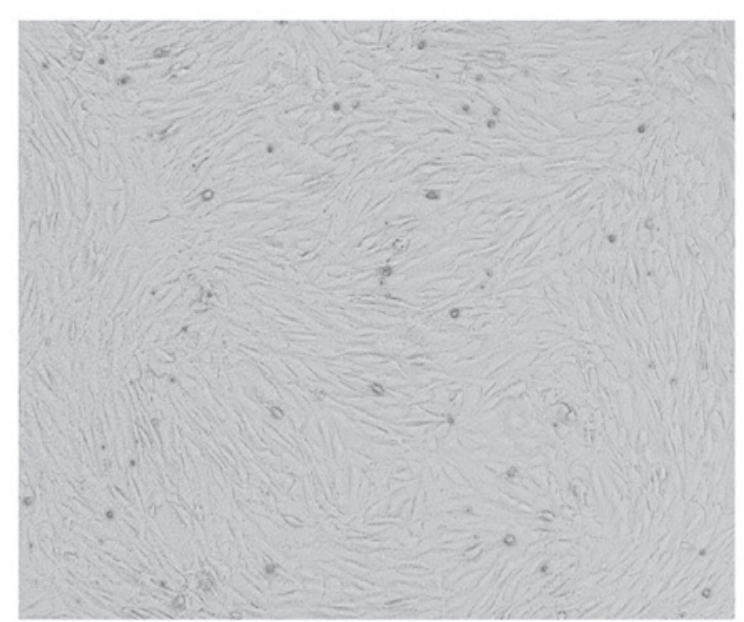

B

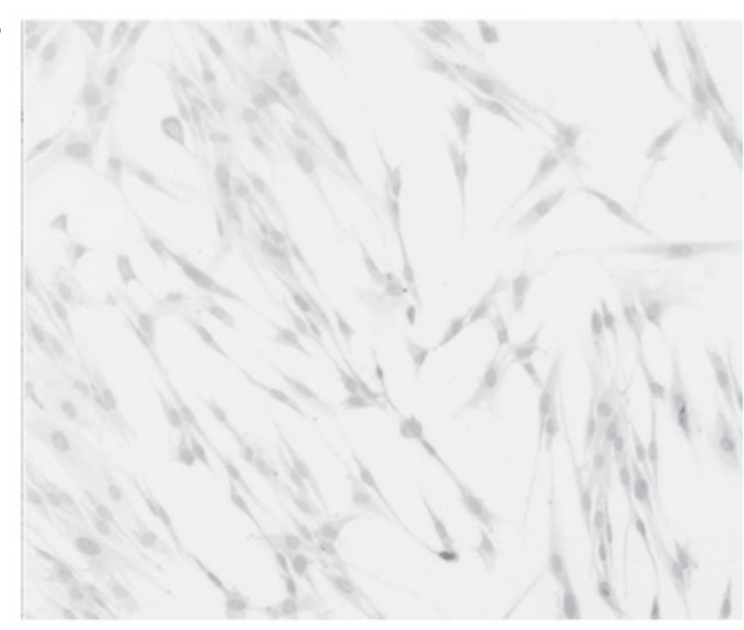

Figure 1. Images of cultured primary atrial myocytes. (A) Primary rabbit atrial myocytes were cultured for $48 \mathrm{~h}$ and observed under an inverted microscope (magnification, x200). (B) Hematoxylin and eosin staining of the atrial myocytes (magnification, x200).

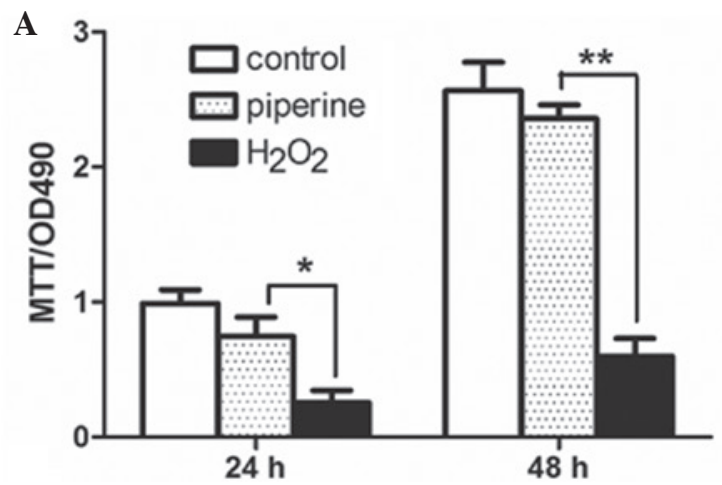

B

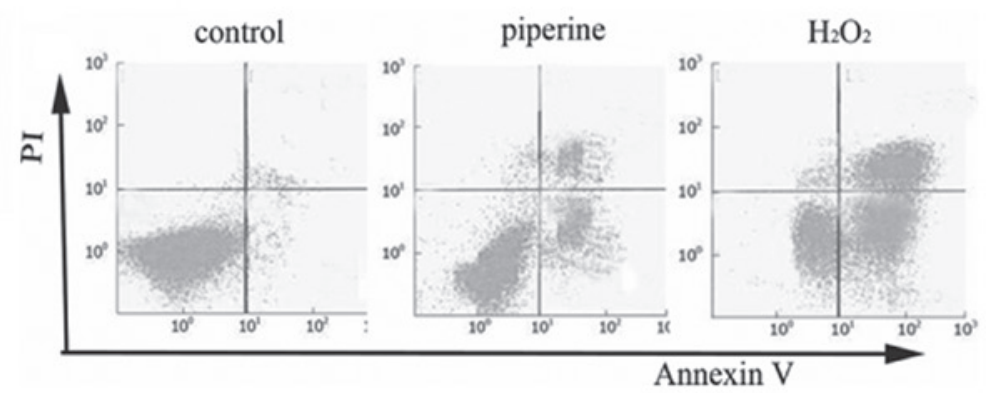

Figure 2. Cell vitality of primary atrial myocytes increased following treatment with piperine. (A) MTT assay. Primary atrial myocytes were cultured for 24 and 48 h. Data are shown as the mean \pm standard deviation of at least three independent experiments on different individuals. ${ }^{*} \mathrm{P}<0.05$ and ${ }^{* *} \mathrm{P}<0.01$ compared with the hydrogen peroxide $\left(\mathrm{H}_{2} \mathrm{O}_{2}\right)$ group. (B) Fluorescence-activated cell sorting (FACS) analysis by Annexin V and propidium iodide (PI). Primary atrial myocytes were cultured for $48 \mathrm{~h}$ and cell apoptosis was detected by FACS.
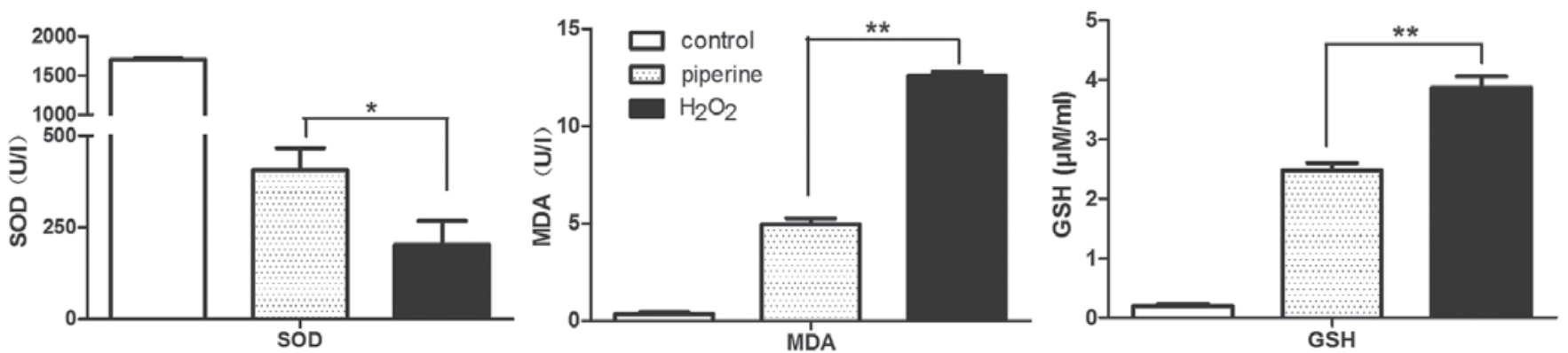

Figure 3. Production of oxidative stress-related markers. Primary atrial cells were cultured and were randomly assigned to three groups: Piperine, hydrogen peroxide $\left(\mathrm{H}_{2} \mathrm{O}_{2}\right)$ and controls. Untreated cells served as a negative control. Data are presented as the mean \pm standard deviation. ${ }^{*} \mathrm{P}<0.05$ and ${ }^{* * *} \mathrm{P}<0.01$. 


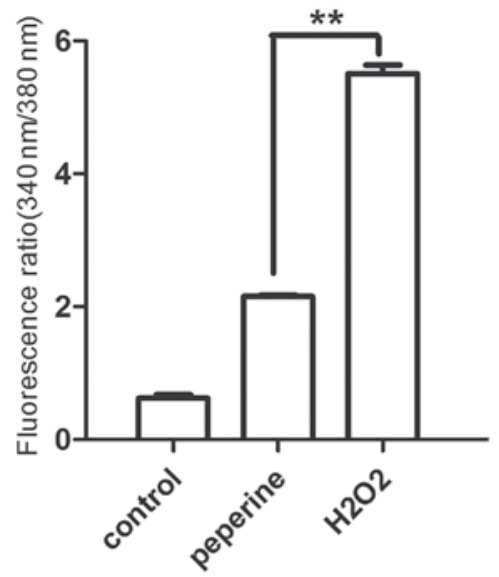

Figure 4. Histogram of intracellular calcium concentration. Activity and variation of intracellular calcium in different groups was detected by fluorescence-activated cell sorting. Data are presented as the mean \pm standard deviation. ${ }^{* *} \mathrm{P}<0.01$ compared with the hydrogen peroxide $\left(\mathrm{H}_{2} \mathrm{O}_{2}\right)$ group.

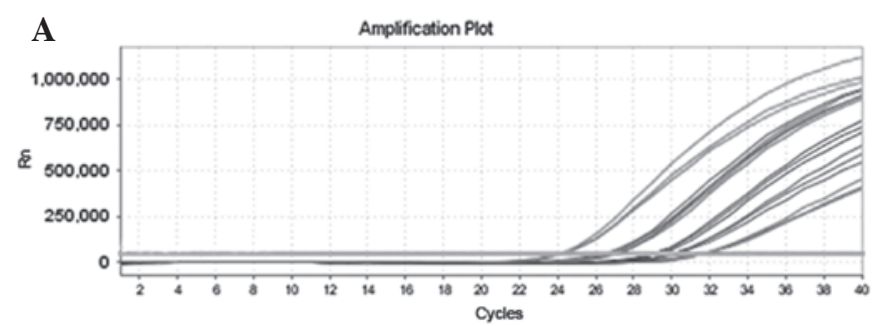

B

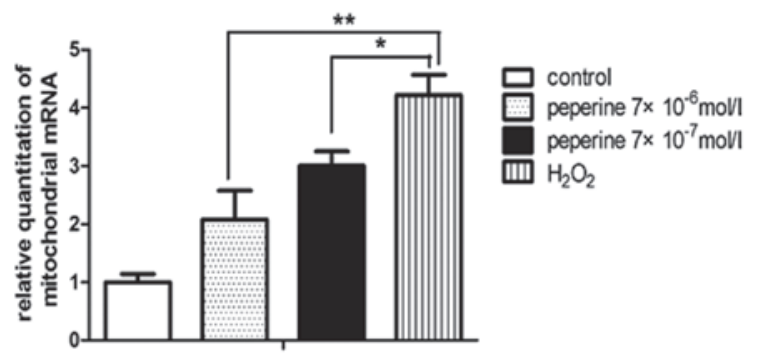

Figure 5. Quantitative polymerase chain reaction in atrial myocytes. (A) Amplification curves of mitochondrial mRNA indicates the specificity of the primer. (B) Histograms of the relative quantitiation of mitochondrial mRNA in different groups. Data are presented as the mean \pm standard deviation. ${ }^{*} \mathrm{P}<0.05$ and ${ }^{* *} \mathrm{P}<0.01$ compared with the hydrogen peroxide $\left(\mathrm{H}_{2} \mathrm{O}_{2}\right)$ group.

$R T$-qPCR in atrial myocytes. Quantitative analysis of mitochondrial mRNA expression levels in atrial myocytes was performed. The results demonstrated that the mitochondrial mRNA expression levels were significantly reduced in the groups treated with piperine compared with those treated with $\mathrm{H}_{2} \mathrm{O}_{2}$ alone $(\mathrm{P}<0.01)$ (Fig. 5). Piperine significantly reduced the mitochondrial mRNA levels in a dose-dependent manner following $\mathrm{H}_{2} \mathrm{O}_{2}$ stimulation as analyzed by RT-qPCR.

\section{Discussion}

Oxidative injury/oxidative stress refers to cell damage resulting from excessive oxidation, when the body produces excessive ROS and/or the antioxidant capacity is reduced (12). The reactive oxygen species (ROS) and secondary ROS, such as peroxynitrite, are mainly generated in the mitochondrial respiratory chain reaction and by monoamine oxidase $(13,14)$. ROS are involved in metabolism and signal transduction, which are important in normal physiology. Under normal circumstances, the body removes reactive oxygen free radicals to maintain ROS production and clearance in a dynamic equilibrium. Certain antioxidants, such as vitamin E, vitamin $\mathrm{C}$, trace elements (including selenium and zinc), SOD and catalase are utilized for ROS clearance $(15,16)$.

SOD is an active protease containing metallic elements, which is present in the cytosol and mitochondria of eukaryotic and prokaryotic cells $(17,18)$. SOD is an important in vivo antioxidant enzyme, which catalyzes the disproportionation reaction of superoxide anion to $\mathrm{H}_{2} \mathrm{O}_{2}$ and oxygen. To a certain extent, SOD activity may reflect the degree of oxidative damage to tissue cells and the body's ability to scavenge free radicals.

GSH is the main source of the sulfhydryl group in the majority of living cells and is important in maintaining the thiol redox state of the sulfhydryl group in proteins (19). In addition, GSH is a key antioxidant in animal cells. Several studies have found that a reduction in GSH levels is an early signal of apoptosis $(20,21)$. In addition to directly scavenging oxygen free radicals, GSH also participates in the myeloperoxidase-derived oxidase reaction to reduce the generation of ROS.

In the present study, SOD activity was significantly increased in the group treated with piperine compared with the group treated with $\mathrm{H}_{2} \mathrm{O}_{2}(\mathrm{P}<0.05)$. Furthermore, the GSH levels were reduced in the piperine group compared with the $\mathrm{H}_{2} \mathrm{O}_{2}$ group $(\mathrm{P}<0.05)$. Thus, piperine may increase the activity of SOD and enhance the activity of antioxidant enzymes to reduce oxidative stress damage to cells.

MDA is a lipid peroxide, which is produced by peroxidation of polyunsaturated fatty acids and induced cell damage (22). In oxidative injury reactions, ROS and macromolecules in the biofilm, including the side chains of polyunsaturated fatty acids and nucleic acids, react to form lipidperoxidation products by lipid peroxidation. The decomposition products of lipid peroxidation may result in cell damage, therefore MDA levels may reflect the extent of lipid peroxidation in the body (23). Simultaneously, MDA levels may also indicate the degree of oxidative damage to cells. The results suggest that piperine effectively reduces oxygen radicals and decreases lipid peroxidation by reducing the attack of polyunsaturated fatty acids by oxygen free radicals (24).

Mitochondria are intracellular organelles where oxidative phosphorylation and ATP synthesis are performed. Mitochondria are semi-autonomous organelles that contain their own genetic machinery and their own genome. Mitochondrial DNA (mtDNA) has a closed circular double-strand structure. Mitochondria are important producers of oxygen free radicals, and mtDNA is vulnerable to oxidative damage and susceptible to mutations as it lacks histone protection and does not have effective repair mechanisms (25) in an environment with high levels of ROS. In addition, when oxidative injury occurs, lipid peroxidation occurs. ROS and polyunsaturated fatty acids react to produce lipid peroxides. The fluidity and permeability of the membrane may change, eventually resulting in changes in cell structure and function. When cells are damaged by $\mathrm{H}_{2} \mathrm{O}_{2}$, mitochondrial 
mtDNA levels undergo a compensatory increase. Piperine can enhance antioxidant enzyme activity, reduce the generation of oxygen free radicals and the oxidative damage of lipid peroxidation to the mitochondrial membrane. Thus, the function of mitochondrial oxidative phosphorylation is protected during the process of oxidative damage.

When oxidative damage was observed to occur, coordination activity between mitochondria-regulating genes and mtDNA was revealed to be impaired, and the oxidative phosphorylation and mitochondrial ATP synthesis abilities were damaged (26). The mtDNA compensatorily increased resulting in the upregulation of mitochondrial mRNA levels $(27,28)$. Additionally, accumulated ROS exert a direct effect on mitochondria, which reduces the membrane potential. When the mitochondrial membrane potential reaches below a threshold value, cell apoptosis is induced (29). In the present study, mitochondrial mtDNA in primary cells was quantitatively analyzed, and the results demonstrated that mRNA expression levels were significantly reduced in the piperine group and the normal group, compared with the $\mathrm{H}_{2} \mathrm{O}_{2}$ group $(\mathrm{P}<0.05)$. However, no significant differences were identified between the piperine group and the control group $(\mathrm{P}>0.05)$. The results revealed that when cells were damaged by $\mathrm{H}_{2} \mathrm{O}_{2}$, mitochondrial copies of mtDNA increased due to functional compensation. Piperine was found to enhance the activity of antioxidant enzymes, inhibit the production of oxygen free radicals, reduce the lipid peroxidation damage on the mitochondrial membrane and partially protect from mitochondrial oxidative phosphorylation.

$\mathrm{Ca}^{2+}$ is a key second messenger in regulating signaling pathways, which is also involved in the activation of enzymes that decompose a variety of proteins, phospholipids and nucleic acids (30). In normal circumstances, $\mathrm{Ca}^{2+}$ enters cells through intracellular calcium channels, proteins located and embedded in the cell membrane. Calcium homeostasis is co-manipulated by $\mathrm{Ca}^{2+}$-translocating enzymes in the plasma membrane and intracellular calcium pool. However, when cells are damaged by oxidative injury, a large quantity of oxygen free radicals are generated $(31,32)$. Lipid peroxidation is induced by oxygen radicals and membrane polyunsaturated fatty acids, which may disrupt the structure of cell membranes. In addition, ATP synthesis is impaired by oxygen free radicals due to mitochondrial damage. In the presence of ROS, activities of the ATP-dependent $\mathrm{Na}^{+}$and $\mathrm{Ca}^{2+}$ pumps in the cell membrane were found to be reduced, the concentration of intracellular $\mathrm{Na}^{+}$ was increased, the rate of $\mathrm{Na}^{+}-\mathrm{Ca}^{2+}$ exchanges was enhanced, and $\mathrm{Ca}^{2+}$ influx was increased (33). In the present study, the concentration of intracellular calcium ions in the $\mathrm{H}_{2} \mathrm{O}_{2}$ group was significantly higher than in the piperine or the normal groups $(\mathrm{P}<0.01)$, which demonstrated that the membrane structures of primary atrial cells were damaged by oxidative injury, and that the accumulation of uncleared oxygen free radicals results in abnormalities of $\mathrm{Na}^{+}-\mathrm{Ca}^{2+}$ exchange in the cell membrane. Thus, intracellular calcium became elevated.

$\mathrm{H}_{2} \mathrm{O}_{2}$-induced oxidative damage may increase the production of oxygen free radicals, reduce the activity of antioxidant enzymes, and promote the peroxidation of polyunsaturated lipid acids and oxidative phosphorylation in mitochondria in primary atrial cells. In the present study, the results demonstrated that piperine extract from Large leaf moss, effectively reduced intracellular accumulation of ROS, decreased damage to cells resulting from lipid peroxidation, protected against mitochondrial oxidative phosphorylation and reduced oxidative injury to mitochondria. Piperine effectively enhanced the activity of antioxidant enzymes, reduced oxygen free radicals, enhanced oxygen radical scavenging and reduced calcium overload damage to cells. Piperine also reduced the effect of oxidative injury on cell viability. In conclusion, piperine exerted a protective function to relieve the oxidative damage to primary atrial myocytes, and has the potential to be used in future to create therapies for oxidative stress injuries.

\section{Acknowledgements}

This study was supported by the National Natural Science Fund (project no. 30772886).

\section{References}

1. Hu Y, Guo DH, Liu P, et al: Antioxidant effects of a Rhodobryum roseum extract and its active components in isoproterenol-induced myocardial injury in rats and cardiac myocytes against oxidative stress-triggered damage. Pharmazie 64: 53-57, 2009.

2. Wang B, Liu P, Shen YM and Dai C: Studies on the chemical constituents from herb of Rhodobryum roseum. Zhongguo Zhong Yao Za Zhi 30: 895-897, 2005 (In Chinese).

3. Dai C, Liu P, Liu C, Wang B and Chen RY: Studies on chemical constituents from moss Rhodobryum roseum II. Zhongguo Zhong Yao Za Zhi 31: 1080-1082, 2006 (In Chinese).

4. Pinho RA, Araujo MC, Ghisi GL and Benetti M: Coronary heart disease, physical exercise and oxidative stress. Arq Bras Cardiol 94: 549-555, 2010 (In Portuguese).

5. Piloni NE, Fermandez V, Videla LA and Puntarulo S: Acute iron overload and oxidative stress in brain. Toxicology 314: 174-182, 2013.

6. Mancuso C, Barone E, Guido P, et al: Inhibition of lipid peroxidation and protein oxidation by endogenous and exogenous antioxidants in rat brain microsomes in vitro. Neurosci Lett 518: 101-105, 2012.

7. Van Wagoner DR: Oxidative stress and inflammation in atrial fibrillation: role in pathogenesis and potential as a therapeutic target. J Cardiovasc Pharmacol 52: 306-313, 2008.

8. Kalpana KB, Srinivasan M and Menon VP: Evaluation of antioxidant activity of hesperidin and its protective effect on $\mathrm{H}_{2} \mathrm{O}_{2}$ induced oxidative damage on pBR322 DNA and RBC cellular membrane. Mol Cell Biochem 323: 21-29, 2009.

9. Mosmann T: Rapid colorimetric assay for cellular growth and survival: application to proliferation and cytotoxicity assays. J Immunol Methods 65: 55-63, 1983

10. Wang XL, Ye D, Peterson TE, et al: Caveolae targeting and regulation of large conductance $\mathrm{Ca}(2+)$-activated $\mathrm{K}^{+}$channels in vascular endothelial cells. J Biol Chem 280: 11656-11664, 2005.

11. Nagai $\mathrm{H}$, Minatoguchi $\mathrm{S}$, Chen $\mathrm{XH}$, et al: Cilnidipine, an $\mathrm{N}+\mathrm{L}$-type dihydropyridine $\mathrm{Ca}$ channel blocker, suppresses the occurrence of ischemia/reperfusion arrhythmia in a rabbit model of myocardial infarction. Hypertens Res 28: 361-368, 2005.

12. Huang XP, Liu XD and Deng CQ: Effects of the combination of active component extracts from Astragalus membranaceus and Panax notoginseng on apoptosis, reactive oxygen species and mitochondrial membrane potential of $\mathrm{PC} 12$ cells with oxidative injury. Zhong Xi Yi Jie He Xue Bao 10: 1127-1134, 2012 (In Chinese).

13. Sato H, Takahashi T, Sumitani K, Takatsu H and Urano S: Glucocorticoid generates ROS to induce oxidative injury in the hippocampus, leading to impairment of cognitive function of rats. J Clin Biochem Nutr 47: 224-232, 2010.

14. Kim J, Seok YM, Jung KJ and Park KM: Reactive oxygen species/oxidative stress contributes to progression of kidney fibrosis following transient ischemic injury in mice. Am J Physiol Renal Physiol 297: F461-F470, 2009.

15. Xu J, Duan X, Yang J, Beeching JR and Zhang P: Enhanced reactive oxygen species scavenging by overproduction of superoxide dismutase and catalase delays postharvest physiological deterioration of cassava storage roots. Plant Physiol 161: 1517-1528, 2013. 
16. Chen WJ, Huang YT, Wu ML, et al: Induction of apoptosis by vitamin D2, ergocalciferol, via reactive oxygen species generation, glutathione depletion, and caspase activation in human leukemia cells. J Agric Food Chem 56: 2996-3005, 2008.

17. Ueda Y, Uehara N, Sasaki H, Kobayashi K and Yamakawa T: Impacts of acute ozone stress on superoxide dismutase (SOD) expression and reactive oxygen species (ROS) formation in rice leaves. Plant Physiol Biochem 70: 396-402, 2013.

18. Gac M, Bigda J and Vahlenkamp TW: Increased mitochondrial superoxide dismutase expression and lowered production of reactive oxygen species during rotavirus infection. Virology 404: 293-303, 2010.

19. Quintana-Cabrera R, Fernandez-Fernandez S, Bobo-Jimenez V, et al: Gamma-glutamylcysteine detoxifies reactive oxygen species by acting as glutathione peroxidase- 1 cofactor. Nat Commun 3: 718, 2012.

20. Park SH and Yu IJ: Effect of dibutyryl cyclic adenosine monophosphate on reactive oxygen species and glutathione of porcine oocytes, apoptosis of cumulus cells, and embryonic development. Zygote 21: 305-313, 2013.

21. Franco R, Panayiotidis MI and Cidlowski JA: Glutathione depletion is necessary for apoptosis in lymphoid cells independent of reactive oxygen species formation. J Biol Chem 282: 30452-30465, 2007.

22. Cheng J, Wang F, Yu DF, Wu PF and Chen JG: The cytotoxic mechanism of malondialdehyde and protective effect of carnosine via protein cross-linking/mitochondrial dysfunction/reactive oxygen species/MAPK pathway in neurons. Eur J Pharmacol 650: 184-194, 2011

23. Spirlandeli AL, Deminice R and Jordao AA: Plasma malondialdehyde as biomarker of lipid peroxidation: effects of acute exercise. Int J Sports Med 35: 14-18, 2013.
24. Feng Z, Hu W, Marnett LJ and Tang MS: Malondialdehyde, a major endogenous lipid peroxidation product, sensitizes human cells to UV- and BPDE-induced killing and mutagenesis through inhibition of nucleotide excision repair. Mutat Res 601: 125-136, 2006.

25. Pan JS, He SZ, Xu HZ, et al: Oxidative stress disturbs energy metabolism of mitochondria in ethanol-induced gastric mucosa injury. World J Gastroenterol 14: 5857-5867, 2008.

26. Kang D and Hamasaki N: Mitochondrial oxidative stress and mitochondrial DNA. Clin Chem Lan Med 41: 1281-1288, 2003.

27. KuwaharaH,ShimazakiM,Kadoya Y,etal:Immunohistochemical localization of two types of carbonic anhydrase isozymes in oncocytoma and oncocytic epithelial cells. Osaka City Med J 35: 121-136, 1989.

28. Richardson TE, Yu AE, Wen Y, Yang SH and Simpkins JW: Estrogen prevents oxidative damage to the mitochondria in Friedreich's ataxia skin fibroblasts. PLoS One 7: e34600, 2012.

29. Higuchi Y: Glutathione depletion-induced chromosomal DNA fragmentation associated with apoptosis and necrosis. J Cell Mol Med 8: 455-464, 2004.

30. Jin C, Wu J, Watanabe M, Okada T and Iesaki T: Mitochondrial $\mathrm{K}^{+}$channels are involved in ischemic postconditioning in rat hearts. J Physiol Sci 62: 325-332, 2012.

31. Belyaeva EA, Korotkov SM and Saris NE: In vitro modulation of heavy metal-induced rat liver mitochondria dysfunction: a comparison of copper and mercury with cadmium. J Trace Elem Med Biol 25 Suppl 1: S63-S73, 2011.

32. Jomova $\mathrm{K}$ and Valko $\mathrm{M}$ : Advances in metal-induced oxidative stress and human disease. Toxicology 283: 65-87, 2011.

33. Badziuk OB, Mazur I and Kosterin SO: Regulation of the mitochondrial ATP-sensitive potassium channel in rat uterus cells by ROS. Ukr Biokhim Zh 83: 48-57, 2011 (In Ukrainian). 